\title{
Microbial mat-related peculiar tunnels and cracks from modern supratidal environment, Gulf of Cambay, India
}

Microbial mat growth on modern hypersaline supratidal environments form wide varieties of features commonly known as microbial matrelated structures (MRS; Schieber et al. 2007; Banerjee et al. 2010). The supratidal flats of the Gulf of Cambay at the west coast of India exhibit prolific microbial mat growth on sands (Fig. a, red line indicating boundary of the state of Gujarat).

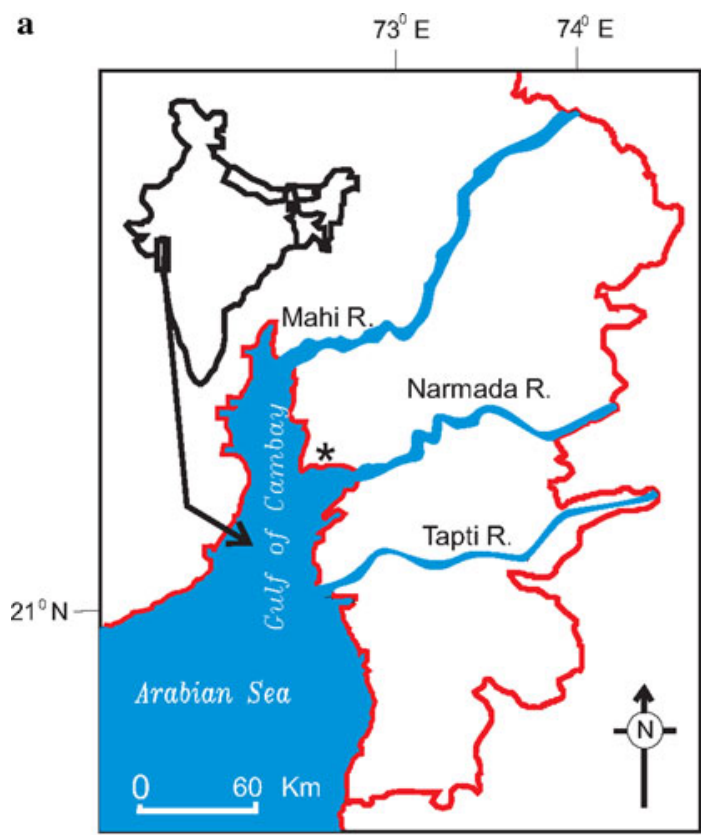

b

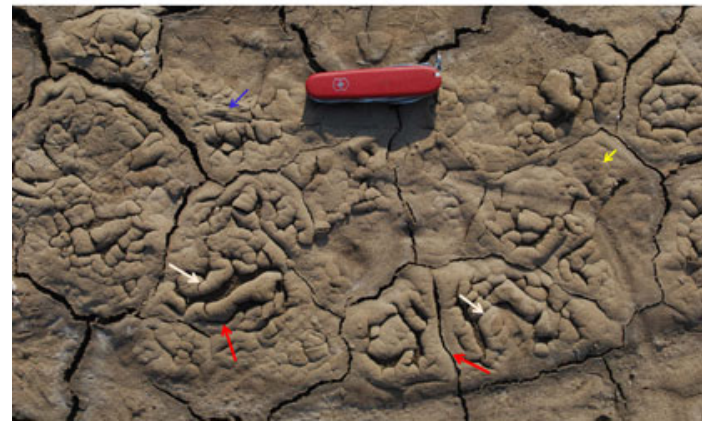

Shrinkage of the mat cover related to drying and desiccation during the ebb tide may form cracks, curls, domes, tunnels and a variety of features. Figure b represents a striking amoeboid structure formed by the interaction between multi-generation undermat gas bubble tunnels and cracks. Competitive growth, twisting, branching and rejoining of the gas migration form tunnels and cracks with laterally variable diameters. The pre-tunnel cracks (red arrows) evidently control gas migration; post-tunnel cracks ran across the tunnels (white arrows). The photograph provides an idea about wide variations in microbial mat-related structures expected in ancient siliciclastic rocks. Ignore the markings related to claws (yellow arrow) and feathers (blue arrow) of birds. Length of the Swiss knife is $91 \mathrm{~mm}$.

\section{References}

Banerjee S, Sarkar S, Eriksson PG, Samanta P (2010) Microbially related structures in siliciclastic sediment resembling Ediacaran fossils: examples from India, ancient and modern. In: Seckbach J, Oren A (eds) Microbial mats: modern and ancient microorganisms in stratified systems. Springer-Verlag, Berlin, pp 111-129

Schieber J, Bose PK, Eriksson PG, Banerjee S, Sarkar S, Catuneanu O, Altermann W (2007) An Atlas of microbial mat features preserved within the siliciclastic rock record. Elsevier Science, Amsterdam, p 311

\footnotetext{
S. Banerjee $(\bowtie)$

Department of Earth Sciences,

Indian Institute of Technology Bombay,

Powai, Mumbai 400076, India

e-mail: santanu@iitb.ac.in
}

Received: 23 March 2013/ Accepted: 5 May 2013/Published online: 26 May 2013

(C) Springer-Verlag Berlin Heidelberg 2013 